\title{
Graphical Approach in Optimization of Penstock Diameter
}

\author{
Navin Kumar Jha \\ Department of Mechanical \& Automobile Engineering, Pashchimanchal Campus, \\ Institute of Engineering, Tribhuvan University, Nepal
}

\begin{abstract}
Penstock is a closed conduit waterway which conveys water from intake to power house. The optimum diameter of penstock is determined through the optimization between the cost associated with friction head loss and the material \& installation cost of penstock. Head loss cost itself depends on power purchase cost, project life and average hours of operation of the power plant and other parameters. This paper first reviews the existing empirical and analytical methods to determine the economical diameter of penstock. Then a simplified arrangement is developed in Ms Excel where the material cost, the cost associated with the head loss in penstock and other parameters which may influence these costs can be analyzed. These costs are plotted in graph and the optimum diameter is calculated graphically. Finally the major parameters affecting the optimum diameter of penstock are identified. It was found that the tariff and material, installation and maintenance cost of penstock are the vital parameters which play the major role during optimization of penstock.
\end{abstract}

Keywords: Penstock, Economic Diameter, Tariff, Optimization, Head Loss.

\section{INTRODUCTION}

The main components of hydropower plant are Intake, Forebay, Penstock, Electromechanical equipment and Control mechanisms. A penstock conveys water from reservoir upto power house and the hydraulic energy is converted into mechanical and finally into electrical energy with the help of electromechanical equipment.

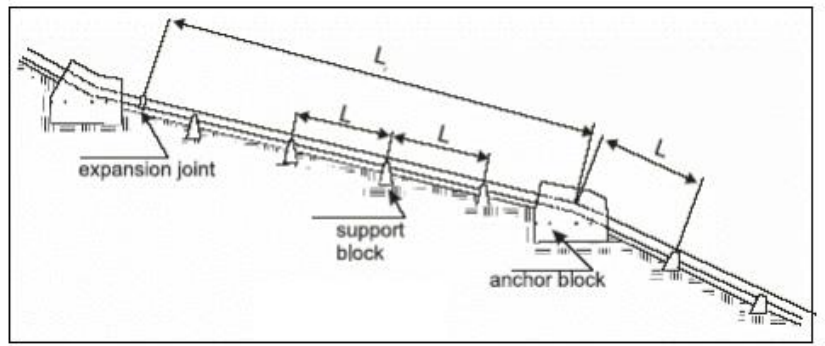

Figure 1: Typical Layout of Penstock [10]

Penstock contributes a relatively significant cost in installation of hydropower and especially in case of Pelton turbine type installation, due to high pressure involved and large length of penstock. So, designers pay much attention for determination of the economic diameter of penstock. The penstock's diameter is determined through an optimization process. For a given design flow, the penstock diameter is inversely proportional to the fluid velocity and thus inversely proportional to the square of the head loss. A parabolic curve relating the cost of the head loss over the powerhouse lifetime for different diameters can then be drawn. Another curve relating the manufacturing and the installation cost of the penstock to its diameter is superimposed on the same graph. The intersection of both curves shown on Fig. 3.4 provides the optimal diameter [1].

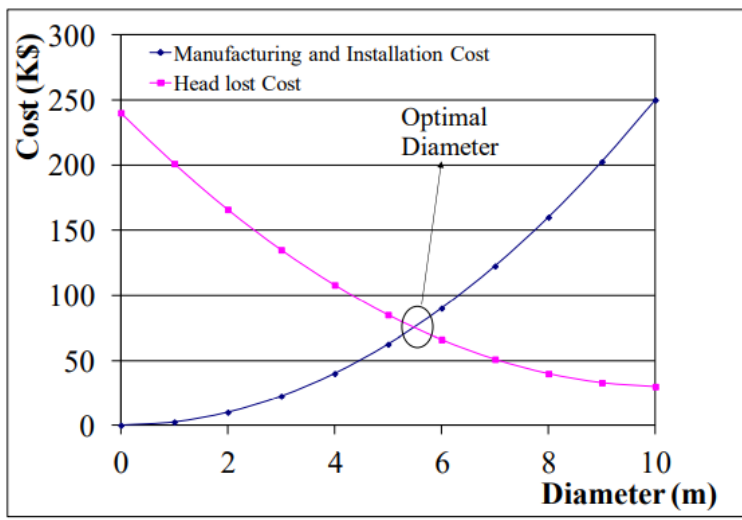

Figure 2: Optimization of Costs [1]

\section{LITERATURE REVIEW}

Indian Standard Criteria for Hydraulic Design of penstock also utilized the same concept and derived the economic diameter by minimizing the annual cost, which includes the cost of power loss due to friction and installation plus maintenance cost of penstock are minimum [2]. Total annual cost was differentiated and equated it to zero which gives

$$
D^{22 / 3}=\frac{2.36 X 10^{6} X Q^{3} X n^{2} X \underset{f}{e} p X C_{s}}{\left[1.39 C_{e}+0.6 C_{c}+\frac{121 H C S(1+i)}{\sigma_{a} X e_{j}}\right] X p}
$$

The notations above are the usual notations [2]. Cost of excavation, concrete lining and cost of steel were calculated in terms of diameter. The thickness of penstock sheet is calculated by hooper stress formula.

Technical Standards of Gates and Penstocks also utilized exactly the similar concept for the optimization of penstock 
but it considered two types of costs and so proposed two different formulae for the determination of economical diameter. The first one is based on the cost of steel penstock and the second one considers the total cost of penstock and the hydraulic turbine generator as the flywheel effect of generator and a steel penstock design may be changed depending upon how to determine the momentary speed variation, the momentary pressure variation of the hydraulic turbine and the required closing time of the governor [3]. Similar concept was adopted and being practiced in academic as well professional design but the empirical formula used for determination of head loss is different.

At the same time some empirical formulae are also being practiced in the determination of economic diameter of penstock and some important empirical relations are:

P.J. Bier's Formula (USBR, 1961):

$$
v=0.125 \sqrt{2} g H
$$

Where $\mathrm{v}=$ permissible velocity in penstock in $\mathrm{m} / \mathrm{s}$.

For given velocity and discharge, the diameter can be calculate [4].

P.J. Bier's Formula (USBR, 1958):

$$
D=0.176 P / H^{0.466}
$$

Where the diameter, $\mathrm{D}$ can be calculated on the basis of available power, $\mathrm{P}$ and head, $\mathrm{H}$ [4]

G. Isakassons Formula:

$$
D=Q^{o .4}
$$

For steel lined shafts at depths from 30 to $80 \mathrm{~m}$ [4]

These empirical formulae were originally developed in F.P.S. unit and it has been converted into SI unit [4].

\section{GRAPHICAL APPROACH FOR COST-DIAMETER OPTIMIZATION IN DETERMINATION OF ECONOMIC DIAMETER}

The above discussions clearly suggest that the economic diameter is the trade-off between annual penstock cost and the cost associated with the head loss which is directly related to the diameter of the penstock. So, here, a simplified annual cost is estimated with several assumptions and the assumptions are made in such that the focus will be given to the major influencing parameters only. The flow chart given below was utilized to develop the arrangement to determine the economic diameter as well for parametric analysis purpose:

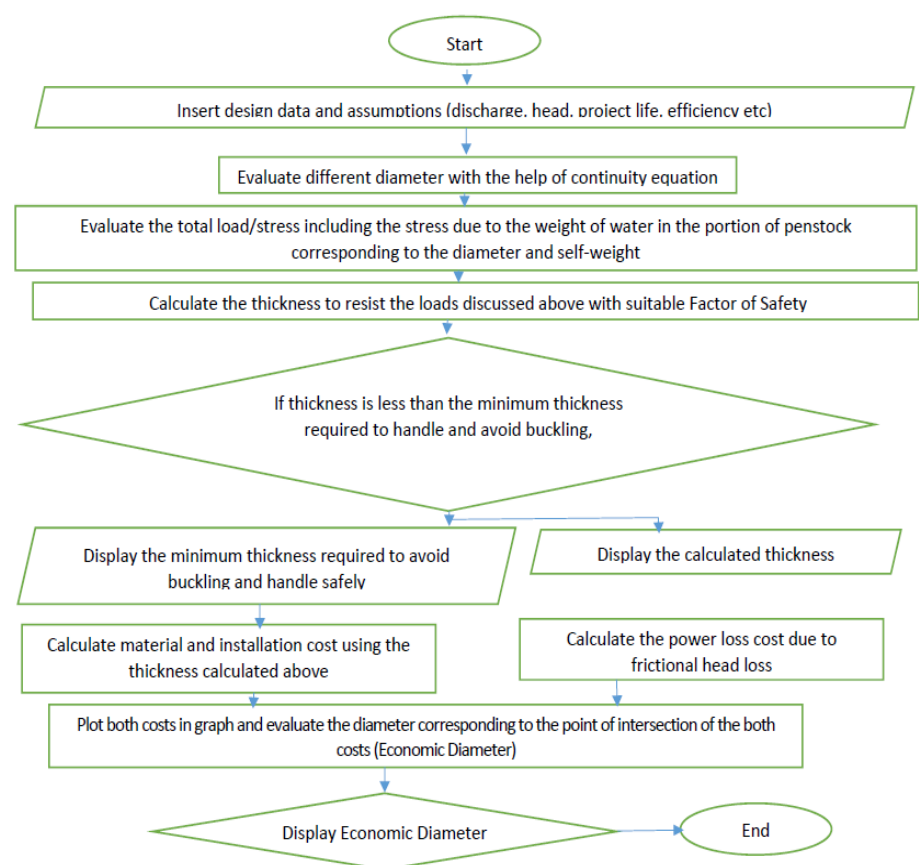

Figure 3: Flow Chart

The diameter is calculated with the help of continuity equation i.e.

$$
Q=A X v=\pi D^{2} / 4
$$

Where $\mathrm{Q}=$ Discharge of the project which includes the sum of design discharge and surge discharge. For different value of velocity and their corresponding diameter, the material cost per unit length (MC) is calculated as

$$
M C=\pi D t \rho p
$$

Where $\mathrm{t}=$ thickness of the penstock material which itself is calculated with the help of hooper formula i.e.

$$
t=1000 \times 9.81 \times H \times D / 2 \sigma
$$

Where $\mathrm{H}=$ Gross head of the plant including water hammer and $\sigma=$ Ultimate strength of the material. The thickness calculated is compared with the minimum thickness prescribed for handling [1] and if it is less than it then the thickness required for shipment and handling to ensure the deflection due to its self load, the prescribed thickness of shell is considered instead of the calculated thickness. Maintenance cost was considered in terms of certain percentage of total cost which itself depends on the site and other geographical conditions. The annual maintenance cost for the penstock was converted in terms of Net Present Value (NPV) with suitable discount rate i.e. the rate of return.

Head loss for particular ' $D$ ' is calculated by Darcy Weisbach equation: 
ISSN (online): 2581-3048

$$
H_{f}=\frac{f v^{2}}{2 X 9.81 X D}
$$

Where $\mathrm{f}=$ friction factor which itself is a function of Reynold Number and the ratio of surface roughness to the diameter of the pipe i.e. $\mathrm{f}=\phi(\mathrm{Re}, \varepsilon / \mathrm{D})$. Reynolds Number is a function of velocity, viscosity and diameter. The viscosity is considered fixed for the study purpose although it is strong function of temperature. It is not easy to determine the functional dependence of the friction factor on the Reynolds number and relative roughness $(\varepsilon / D)$. Much of this information is a result of experiments conducted by $\mathrm{J}$. Nikuradse in 1933 and amplified by many others since then [5]. One difficulty lies in the determination of the roughness of the pipe. Even for smooth pipes the friction factor is not zero. That is, there is a head loss in any pipe, no matter how smooth the surface is made. There is always some microscopic surface roughness even in hydraulic smooth pipe that produces the noslip behavior on the molecular level, even when the roughness is considerably less than the viscous sublayer thickness. Various investigators have attempted to obtain an analytical expression for $\mathrm{f}=\phi(\mathrm{Re}, \varepsilon / \mathrm{D})$. Here the following Colebrook equations were considered for the study purpose as it was used in Moody Chart. Also it is widely used in design and selection of hydraulic pipe [6]:

$$
f=\frac{64}{R e}
$$

Where $\operatorname{Re} \leq 2100$ for laminar flow and

$$
R e=\frac{v D}{\mathrm{Y}}
$$

https://doi.org/10.47001/IRJIET/2020.408005

Here, $\mathrm{Re}=$ Reynold's Number

$\mathrm{v}=$ Velocity of water

$\mathrm{D}=$ Diameter of Penstock and

$\Upsilon=$ Kinematic Viscosity of Water

$\mathrm{f}=$ Frictional factor

$$
f=\frac{1.325}{\left[\ln \left(\frac{e}{3.7 D}+\frac{5.74}{R e^{0.9}}\right)\right]^{2}}
$$

For $5000 \leq \operatorname{Re} \leq 108$, turbulent flow and $10-6 \leq \mathrm{e} / \mathrm{D} \leq 10-2$.

Here, e $=$ Roughness height of the internal surface of penstock material. The type of flow in penstock is mostly considered turbulent in nature and the surface roughness is within the range of the value prescribed for equation (11), the equation was considered for this study.

The cost associated with the frictional head loss $(\mathrm{PC})=\eta$ X $\mathrm{H}_{\mathrm{f}}$ X Q X 9.81/1000 kilo watt X 365 X Project Life Year X Working Hour $X$ Tariff. Here the efficiency stands for the overall efficiency of the plant assuming whatever the head loss is not solely the loss in terms of money rather it depends on how much of that quantity would be converted into useful power. Here the working day was used 365 days per year for simplicity.

The above relations were used in the calculations of the cost for different value of diameter or for different velocity. The costs were plotted versus diameter in excel to find the optimum diameter of the penstock.

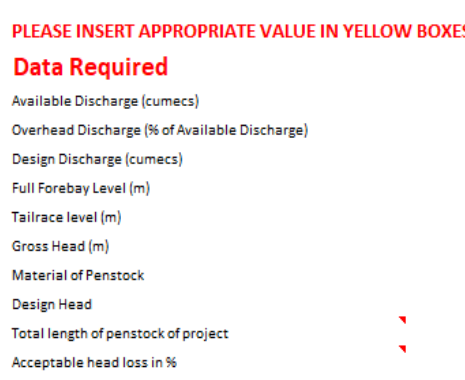

Compute Thickness

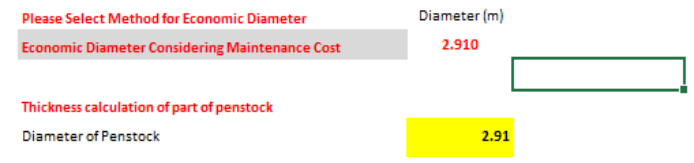

Figure 4: Sample Display of Input Parameters

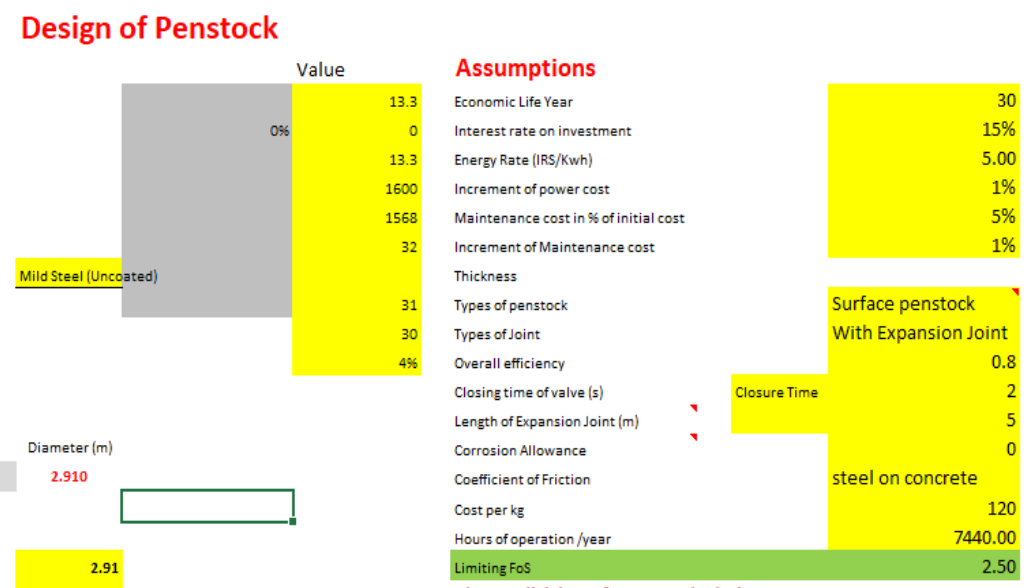

2.50 
ISSN (online): 2581-3048

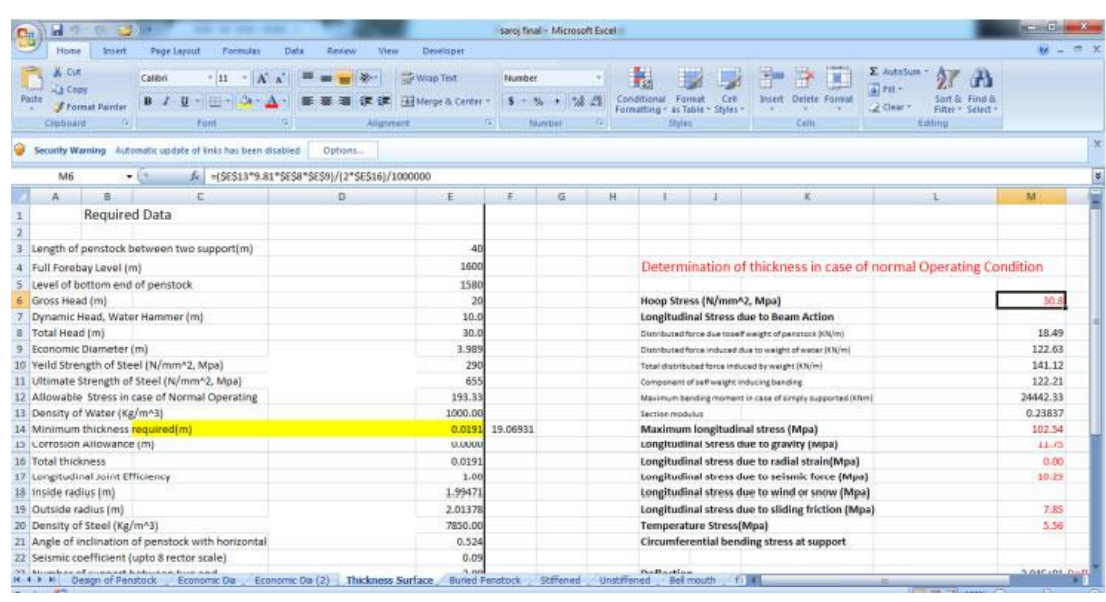

Figure 5: Calculation of Thickness

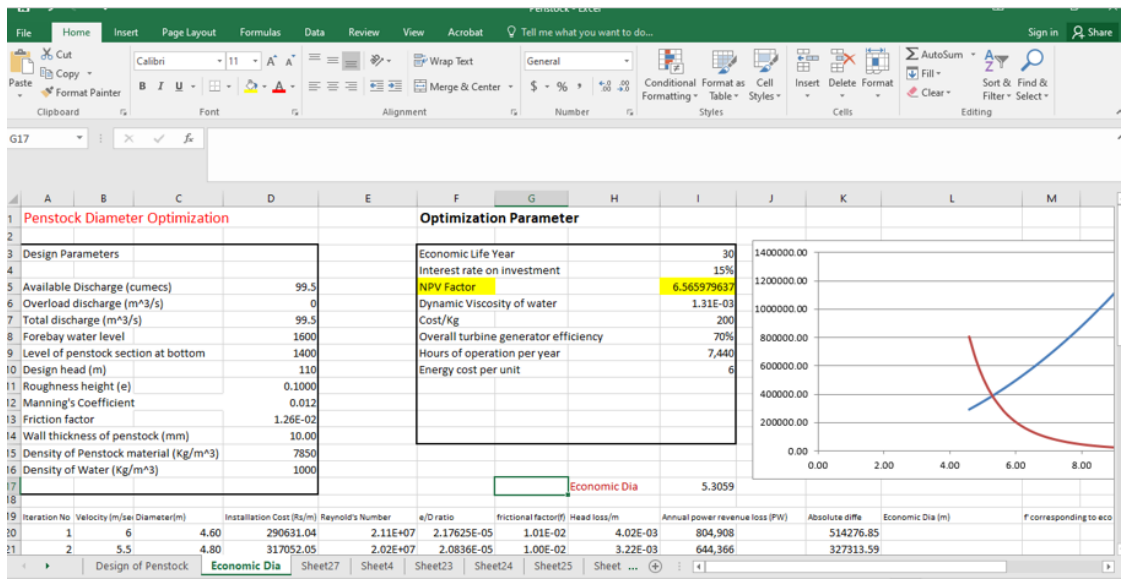

Figure 6: Economic Diameter Display

\section{RESULTS AND DISCUSSIONS}

The above arrangement/software is based on the several assumptions and less significant parameters were not considered here. So it was necessary to validate the arrangement by the determination of economic diameter of few existing hydropower projects and comparison with the already designed value of it.

Table 1: Comparison of Already Designed Diameter and Calculated Diameter of Few Existing Hydropower Plant

\begin{tabular}{lccc}
\hline Project & $\begin{array}{c}\text { Head } \\
(\mathbf{m}) / \text { Discharge } \\
\left(\mathbf{m}^{3} / \mathbf{s}\right)\end{array}$ & Calculated & Designed \\
\hline $\begin{array}{l}\text { Sunkoshi } \\
\text { Hydropower Plant }\end{array}$ & $110 / 13.3$ & 2.78 & 2.54 \\
Kaligandaki & $130 / 44.86$ & 4.71 & 5.25 \\
Hydropower Plant & & & \\
Upper Chamelia & $215 / 22.79$ & 3.03 & 3.1 \\
Hydropwer Project & & & \\
\hline
\end{tabular}

Typical projects were considered to validate the study as it covers different range of gross head and design discharge. Also, due consideration was made to make sure that then tariff and material \& maintenance cost is realistic. The optimum diameter calculated is slightly different from the already designed value. The reasons are the parameter which affects the optimization process and mainly material cost and tariff rate. Despite these, the very close values of economic diameter were calculated for some hydro powers which have been running in European countries under different tariff condition $[9,10]$ which further reaffirms that the developed software/arrangements and considerations are valid.

Each parameter was varied to find the impact of the parameter in the economic diameter keeping other parameters constant and pattern was studied. The graphs were shown in Fig. 7, Fig. 8, Fig. 9, Fig. 10 and Fig. 11 which clearly suggests that the tariff, material \& maintenance cost and Return on Investment rate are the significant parameter which dictates the optimization of penstock diameter. The surface roughness factor can also play an important role here but the choice of material commercially available for this purpose is limited and so attention should be paid to select the material 
for which manufacturers claim smooth surface. Overall Efficiency and Project Life has least impact in the optimization of the diameter but the working days and working hour has direct impact on the cost associated with head loss and so it should be considered seriously.

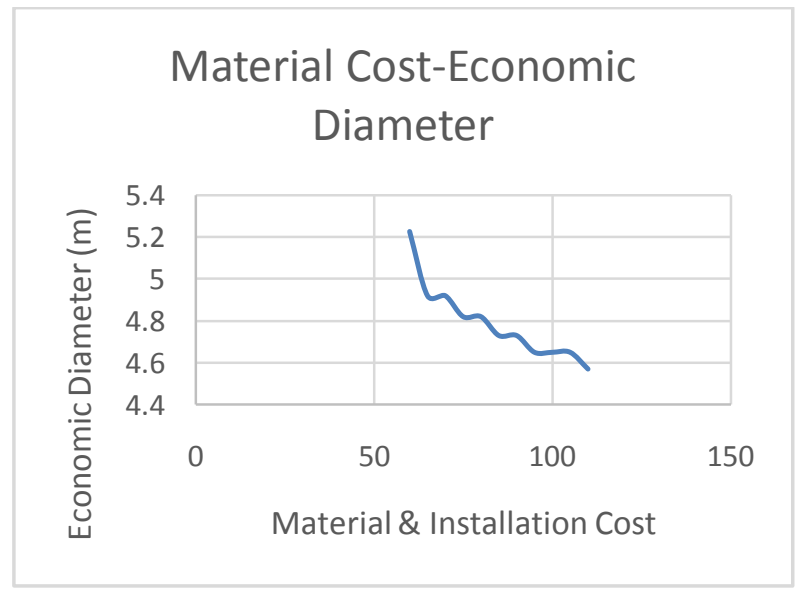

Figure 7: Material Cost - Economic Diameter

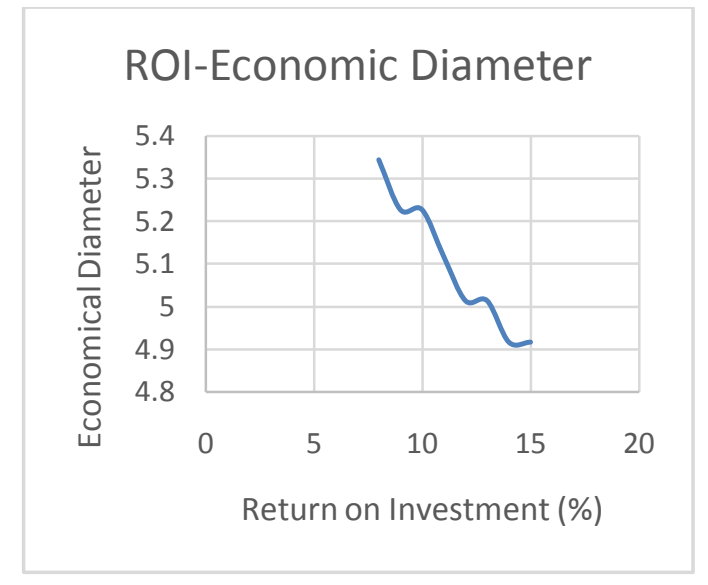

Figure 8: Return on Investment - Economic Diameter

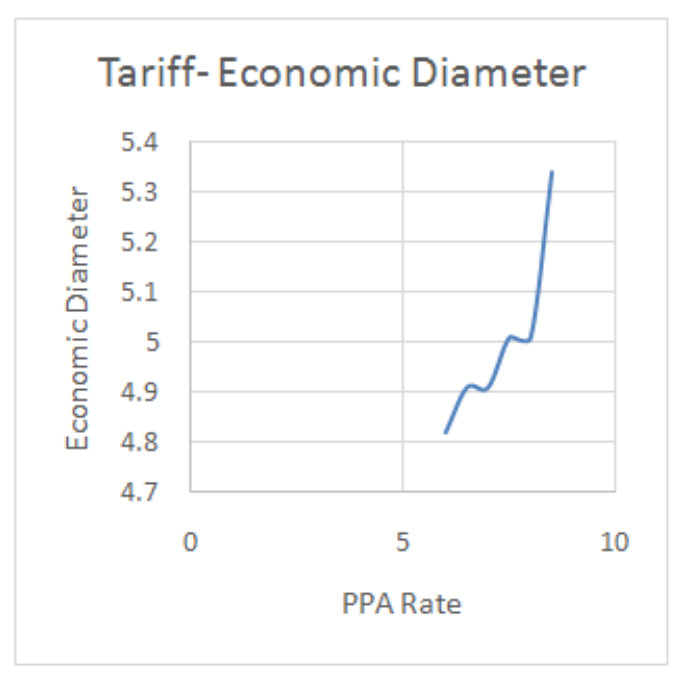

Figure 9: Tariff- Economic Diameter
https://doi.org/10.47001/IRJIET/2020.408005

\section{Economic Diameter- \\ Project Life}

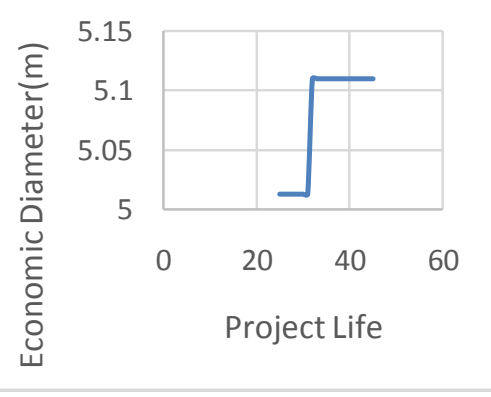

Figure 10: Economic Diameter - Project Life

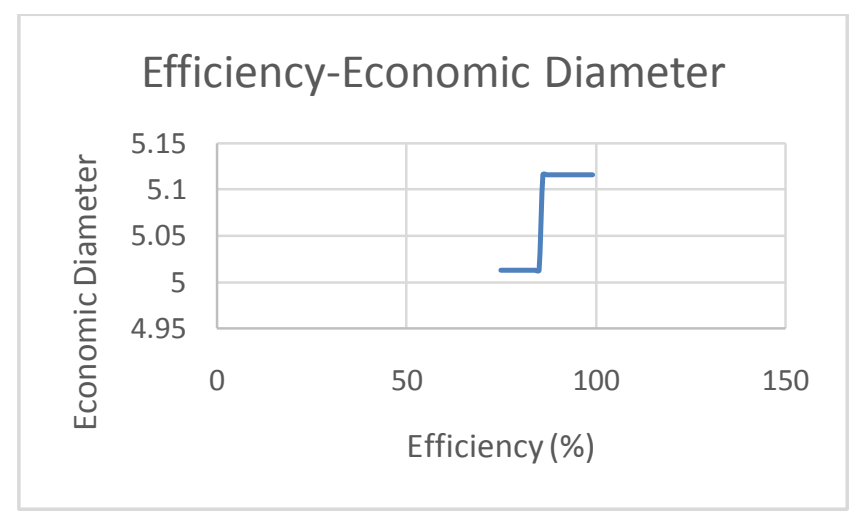

Figure 11: Efficiency - Economic Diameter

\section{CONCLUSION}

Optimization of penstock diameter, especially in the case where the length is significant, is a challenging job for designer as it depends on the several parameters. Different analytical and empirical approaches are in use and several engineering codes have been developed. The main idea which is used during optimization of the diameter of penstock is to minimize the total cost i.e. Material cost and cost associated with head loss which themselves depends on tariff rate, return on investment, project life and overall efficiency of the plant. Mathematically, minimizing the total cost is differentiating the total cost and equating it to zero. Here the graphical approach was developed where both costs were plotted against the diameter and the optimum diameter was calculated as the diameter corresponding to the point of intersection of the cost curves. Optimum diameter for few existing hydropower plants were calculated for validation purpose. Finally the arrangement in Ms Excel was used to identify the major parameters which may impact during optimization process. Material cost, cost associated with frictional power loss and the parameters like return on investment and PPA rate were identified as the major role player during optimization. 
ISSN (online): 2581-3048

Volume 4, Issue 8, pp 25-30, August-2020 https://doi.org/10.47001/IRJIET/2020.408005

\section{REFERENCES}

[1] D. Bernard, "Numeric Modelling of Water Hammer in Penstocks," M.Sc. Thesis, Department of Civil Engineering, Faculty of Engineering, University of Ottawa, Canada, 2013.

[2] Indian Standard, "CRITERIA OF HYDRAULIC DESIGN OF PENSTOCK," IS: 11625-1986 Reaffirmed 2001, India, 2001.

[3] Hydraulic Gate and Penstock Association, "Technical standards for gates and penstocks", Japan, 1986.

[4] R.S. Varshney, "Hydro Power Structures," India, 2010.

[5] United States Department of the Interior Bureau of Reclamation, "A Water Resource Technical Publications, Engineering Monograph No 3, Welded Steel Penstocks", 1986.
[6] R. Hardee. (2015). Calculating Head Loss in a Pipeline.

Available: https://www.pumpsandsystems.com/pumps/april2015-calculating-head-loss-pipeline [Accessed: 6August 2020].

[7] N.E. Authority, "Generation Directorate (Edition 11)," Nepal, 2019.

[8] http://apipower.com.np/home/pagesDisp/naugarhgad-hydroelectric-project-8-5mw\#: :text=The\%20powerhouse $\% 20$ consists $\% 20$ of $\% 20$ two,of\%20the $\% 20$ Project $\% 20$ is $\% 20$ NRs.

[9] Layman, "Handbook on How to Develop a Small Hydro Site", European Commission, 1998.

[10] European Small Hydropower Association - ESHA, "Guide on How to Develop a Small Hydropower Plant", 2004.

\section{Citation of this Article:}

Navin Kumar Jha, "Graphical Approach in Optimization of Penstock Diameter" Published in International Research Journal of Innovations in Engineering and Technology - IRJIET, Volume 4, Issue 8, pp 25-30, August 2020. https://doi.org/10.47001/IRJIET/2020.408005 